\title{
C-S-H Pore Size Characterization Via a Combined Nuclear Magnetic Resonance (NMR)-Scanning Electron Microscopy (SEM) Surface Relaxivity Calibration
}

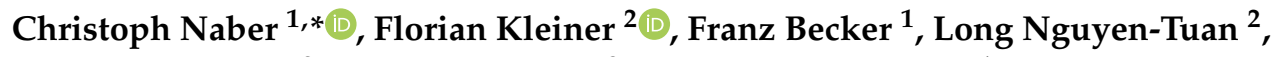 \\ Christiane Rößler ${ }^{2}$, Merlin A. Etzold ${ }^{3}$ and Jürgen Neubauer ${ }^{1}$ \\ 1 GeoZentrum Nordbayern, Mineralogy, University of Erlangen-Nuernberg (FAU), Schlossgarten 5a, \\ 91054 Erlangen, Germany; franz.becker@fau.de (F.B.); juergen.neubauer@fau.de (J.N.) \\ 2 F. A. Finger-Institute for Building Materials Science, Bauhaus-University Weimar, Coudraystraße 11A, \\ 99423 Weimar, Germany; florian.kleiner@uni-weimar.de (F.K.); long.nguyen.tuan@uni-weimar.de (L.N.-T.); \\ christiane.roessler@uni-weimar.de (C.R.) \\ 3 Department of Applied Mathematics and Theoretical Physics, University of Cambridge, Wilberforce Road, \\ Cambridge CB3 0WA, UK; mae38@cam.ac.uk \\ * Correspondence: christoph.naber@fau.de
}

Received: 6 March 2020; Accepted: 7 April 2020; Published: 10 April 2020

check for updates

\begin{abstract}
A new method for the nuclear magnetic resonance (NMR) surface relaxivity calibration in hydrated cement samples is proposed. This method relies on a combined analysis of 28-d hydrated tricalcium silicate samples by scanning electron microscopy (SEM) image analysis and ${ }^{1} \mathrm{H}$-time-domain (TD)-NMR relaxometry. Pore surface and volume data for interhydrate pores are obtained from high resolution SEM images on surfaces obtained by argon broad ion beam sectioning. These data are combined with $T_{2}$ relaxation times from ${ }^{1} \mathrm{H}$-TD-NMR to calculate the systems surface relaxivity according to the fast exchange model of relaxation. This new method is compared to an alternative method that employs sequential drying to calibrate the systems surface relaxivity.
\end{abstract}

Keywords: nuclear magnetic resonance (NMR); scanning electron microscopy (SEM); pore size distribution; calcium silicate hydrate; tricalcium silicate

\section{Introduction}

The nature of the pore space in hydrated cement is essential for the buildup of final strength in concrete constructions. Fewer and smaller pores in concrete lead to higher compressive strength. The pore space is difficult to access in its entirety due to the wide range of length scales starting from nanometer size interlayer and gel pores in C-S-H, to interhydrate pores between individual hydrate phases, and micrometer size capillary pores. Commonly used techniques to measure the pore volume, like mercury intrusion porosimetry or gas adsorption, are not sensitive to C-S-H porosity [1]. Furthermore, they require a water removal step prior to the measurement. This can induce artifacts, especially for interlayer and gel pores depending on the drying method used [2].

In contrast, no pore water is removed during sample preparation prior to measurements employing ${ }^{1} \mathrm{H}$ time-domain nuclear magnetic resonance relaxometry $\left({ }^{1} \mathrm{H}\right.$-TD-NMR). With this technique the water in the pores is the probe and thus does not need to be removed. As ${ }^{1} \mathrm{H}-\mathrm{TD}-\mathrm{NMR}$ is sensitive to all protons present in the sample, it is also suited to measure nanoscale water-filled pores in the C-S-H structure $[3,4]$ and to quantify the amount of hydrate phases developed and mixing water consumed during cement hydration $[3,5,6]$. 
Several NMR methods to study the pore space in hydrated cements have been proposed. McDonald et al. [4] used solid-echo (SE) pulse sequences to measure gradually dried cement pastes. They plotted the NMR signal intensity of these samples against the sample mass and found three distinct drying stages. Through a series of geometrical considerations and assumptions about the state of water, they acquired measures for two types of C-S-H pores. Muller et al. [3] used the fast exchange model of relaxation $[7,8]$ to quantify the surface-to-volume ratio of the gel and interlayer pore space of C-S-H. This model requires an a priori unknown parameter, the surface relaxivity, which they calibrated from the $T_{2}$ relaxation time measured at a sample equilibrated at low relative humidity conditions. They assume that in these conditions all surfaces in the sample were covered by a monolayer of water, which they assumed to consist of two monolayers of water molecules adsorbed to each layer of the interlayer space. In both methods described above, the calibration of the surface relaxivity was solely based on one measurement technique, ${ }^{1} \mathrm{H}-\mathrm{TD}-\mathrm{NMR}$, with assumptions about either the geometrical nature of the pore space or the physico-chemical nature of the pore surfaces. Cross referencing the findings with an additional measurement technique would help to check the validity of the methods.

In this work, we propose a new method to calibrate the system's surface relaxivity based on a combination of SEM imaging and ${ }^{1} \mathrm{H}$-TD-NMR measurements. The SEM sample preparation adapted the argon broad ion beam (Ar-BIB) technique used for sandstones [9] for hydrated tricalcium silicate. High resolution SEM imaging and following image analysis was applied to prepared surfaces. The advantage of this method is that large surfaces $\left(\mathrm{mm}^{2}\right)$ are sectioned without destruction of nanoscale structures. The achievable resolution for SEM imaging of porous materials is therefore independent of the sample preparation. It only depends on the imaging performance of the electron microscope used [9].

The method applied in the present study relies on image analysis of the interhydrate pore size. Thus, the surface relaxivity calibration was performed on the larger pores in hydrated tricalcium silicate $\left(\mathrm{C}_{3} \mathrm{~S}\right)$ that should not have been altered due to drying of the sample. This new method was tested against, and compared with, the drying method presented by Muller et al. [3] assuming monolayer water molecule coverage in the interlayer space, the smallest pores in hydrated $\mathrm{C}_{3} \mathrm{~S}$. Both methods were conducted on hydrated monoclinic $\mathrm{C}_{3} \mathrm{~S}$ pastes.

Electron-microscopic imaging and analysis techniques are advancing fast with increasing computing power and ${ }^{1} \mathrm{H}-\mathrm{TD}-\mathrm{NMR}$ is established as a standard analysis method in the cement industry $[10,11]$. This ongoing development will increase the demand for measurement methods that put the acquired devices to use, such as the method presented in this work. The demonstrated pore space investigation will help in the design of new mortar and concrete formulations with enhanced physical properties due to an optimized pore space distribution.

\section{Materials and Methods}

\subsection{Materials}

Commercially available tricalcium silicate $\left(\mathrm{C}_{3} \mathrm{~S}\right)$ (Vustah, Czech Republic) of the MIII polymorph was used for the investigations. The chemical composition measured by $\mathrm{X}$-ray fluorescence spectroscopy (XRF) is shown in Table 1. Phase purity of the $C_{3} S$ was checked by $X$-ray diffraction ( $97.6 \mathrm{wt}$. $\%$ crystalline $C_{3} S$ ).

Table 1. Chemical composition of the used $C_{3} S$ measured by X-ray fluorescence spectroscopy (XRF).

\begin{tabular}{cc}
\hline Oxides [wt.\%] & $\mathrm{C}_{3} \mathrm{~S}$ \\
\hline $\mathrm{SiO}_{2}$ & 26.5 \\
$\mathrm{TiO}_{2}$ & 0.03 \\
$\mathrm{Al}_{2} \mathrm{O}_{3}$ & 0.34 \\
$\mathrm{Fe}_{2} \mathrm{O}_{3}$ & 0.07 \\
$\mathrm{Mn}_{2} \mathrm{O}_{3}$ & 0.02 \\
$\mathrm{MgO}$ & 2.02 \\
$\mathrm{CaO}$ & 70.3 \\
$\mathrm{Na}_{2} \mathrm{O}$ & 0.04 \\
\hline
\end{tabular}


Table 1. Cont.

\begin{tabular}{cc}
\hline Oxides [wt.\%] & $\mathrm{C}_{3} \mathrm{~S}$ \\
\hline $\mathrm{K}_{2} \mathrm{O}$ & 0.03 \\
$\mathrm{P}_{2} \mathrm{O}_{5}$ & 0.13 \\
LOI & 0.46 \\
\hline$\sum$ [wt.\%] & 99.8 \\
\hline
\end{tabular}

For all experiments, the $\mathrm{C}_{3} \mathrm{~S}$ was mixed with deionized water and hydrated for $28 \mathrm{~d}$ in sealed containers. To obtain a completely water saturated microstructure, the samples for NMR measurements were additionally covered with a thin layer of saturated portlandite solution after one day of hydration.

\subsection{Pore Size Evaluation}

Pore sizes were determined by employing ${ }^{1} \mathrm{H}-\mathrm{TD}-\mathrm{NMR}$ and a surface relaxivity calibration via two alternative methods, i) sequential drying of the C-S- $\mathrm{H}$ to a monolayer $\mathrm{H}_{2} \mathrm{O}$ coverage $[3,12]$, and ii) combination of SEM image analysis and ${ }^{1} \mathrm{H}$-TD-NMR measurements. The ${ }^{1} \mathrm{H}$-TD-NMR measurements were performed on a Bruker minispec mq20 spectrometer operating at $19.95 \mathrm{MHz}$. The temperature controlled probe head, with a dead time around $5.4 \mu \mathrm{s}$, was set at $23{ }^{\circ} \mathrm{C} . \mathrm{T}_{2}$ spin-spin relaxation measurements were performed using solid-echo [13] (also called quadrature-echo) and CPMG (Carr-Purcell-Meiboom-Gill) $[14,15]$ pulse sequences. The $T_{2}$ relaxation results were evaluated using Gaussian and exponential decay functions for the solid-echo measurements [13] and multiexponential fitting (sum of four exponential decay functions, Levenberg-Marquard fitting algorithm) for the CPMG measurements. The measurements were repeated twice using a total of three individually prepared samples.

The fast exchange model $[7,8]$ gives a relationship between the surface-to-volume ratio $(S / V)$ of pores and the resulting $T_{1}$ and $T_{2}$ relaxation times,

$$
\frac{1}{T_{2}} \approx \frac{S}{V} \times \lambda
$$

where $\lambda$ is the surface relaxivity, which highly depends on the individual sample surface chemistry. This equation was used in both of the following calibration methods. For interlayer and gel pores, a planar pore geometry was assumed, where $S=2 A$ and $V=A d$. Thus $S / V=2 / d$ for planar pores. For interhydrate pores a spherical shape was assumed, where $S / V=6 / d$.

\subsubsection{Determination of the Surface Relaxivity from Monolayer $\mathrm{H}_{2} \mathrm{O}$ Coverage}

In order to reach a monolayer $\mathrm{H}_{2} \mathrm{O}$ coverage of the C-S-H interlayer pore space, 28-d hydrated samples were gradually dried in a laboratory furnace with temperatures increasing from $23^{\circ} \mathrm{C}$ to $120^{\circ} \mathrm{C}$. Overall, 16 drying steps were made and the samples were measured in between drying steps using solid-echo and CPMG pulse sequences, as described above. The resulting $T_{2}$ relaxation time for the C-S-H interlayer water at maximum drying conditions was combined with a water monolayer thickness of $0.28 \mathrm{~nm}$ [16], following Muller et al. [3], to calculate the surface relaxivity using Equation (1). This surface relaxivity was in turn used to calculate the $S / V$ ratio and pore diameters of the water-saturated interlayer, gel, and capillary pore spaces, employing the individual $T_{2}$ relaxation times measured for the non-dried samples.

\subsubsection{Combination of TD-NMR and SEM}

To be able to acquire high resolution SEM images of the 28-d hydrated samples, argon broad ion beam sectioning was used for sample preparation. This preparation method avoids artifacts like scratches or smearing on the surface of the specimen, in comparison to the regular polishing. Furthermore, it is not necessary to embed the specimen in resin. 
The $C_{3} S$ hydration process was stopped after $28 \mathrm{~d}$ by immersing the specimen in ethanol $(98 \%)$ for $20 \mathrm{~min}$. Afterwards, the specimen was dried at $40{ }^{\circ} \mathrm{C}$ for several hours. A $7 \times 3 \times 5 \mathrm{~mm}^{3}$ piece was dissected. It was then milled in a Leica EM TIC 3X, an Ar-BIB milling system(Leica Microsystems, Wetzlar, Germany), using three ion beams and a stationary sample holder at $6 \mathrm{kV}$ with a $2 \mathrm{~mA}$ gun current for $3 \mathrm{~h}$ followed by another $3 \mathrm{~h}$ treatment at $3 \mathrm{kV}$ and $1 \mathrm{~mA}$.

The specimen was then analyzed using a FEI Nova NanoSEM scanning electron microscope without a conductive coating. The images were acquired using the through the lens secondary electron (TLD SE) detector. Subjects of the analysis were mainly areas containing dense C-S-H phases with very little or no preparation damage. Since the specimen was highly sensitive to the electron beam and the thereby induced heat, low voltage, low current settings $(2 \mathrm{kV}, 22 \mathrm{pA})$ and a short observation time were mandatory to achieve high magnifications without affecting the pore structure.

The image analysis was performed using the open source software Fiji [17] and self-developed macros, which can be found online [18]. A semi-automated process was used to segment the pores. Twenty-five images (a cumulative area of $192 \mu \mathrm{m}^{2}$ ) with the same magnification (approx. $2.91 \times$ $2.91 \mathrm{~nm}^{2} / \mathrm{px}$ ) and containing mostly porous areas were analyzed. The images were optimized for segmentation (non-local means denoising, contrast enhancement) and the pores were segmented using the automatic thresholding method by Phansalkar et al. [19] utilizing modified parameters (radius $=6 \mathrm{px}, k=0.15$, and $r=0.3$, see elsewhere for details [18]). After the application of morphological operators ('despeckle' and 'fill holes') to denoise the binary images, the chord-length density function (CDF) [20](Chapter 2.5) of areas identified as pores was calculated in $x$ and $y$-directions to improve the data density. While it is possible to calculate the pore size distribution (PSD) directly, the area analyzed was insufficient to determine a mean interhydrate pore size. Therefore, the CDF was determined as PSD. Nevertheless, it should be noticed that it is not trivially possible to convert the CDF to a PSD for non-circular polydisperse pores or particles. Therefore, the CDF might have led to a slightly translated (overestimated) interhydrate pore size.

The mean interhydrate pore size was determined from the resulting pore size distribution. This was combined with the longest interhydrate $T_{2}$ relaxation time, expected to correspond to the interhydrate pores, in order to calculate the surface relaxivity $\lambda$ according to Equation (1). The surface relaxivity was then used again to calculate the $S / V$ ratio and pore diameters of the interlayer and gel pore spaces for the samples.

\section{Results and Discussion}

Figure 1 shows an exemplary solid-echo $T_{2}$ magnetization decay of a 28-d hydrated $C_{3} S$ sample. The decay was fit with a Gaussian decay function to account for the protons rigidly bound, and two exponential functions for the more mobile protons in the sample [13]. In NMR $T_{2}$ measurements rigidly bound protons, for example protons bound in a crystal structure, exhibited shorter $T_{2}$ times while protons loosely bound, for example protons of the pore water, exhibited longer $T_{2}$ times. The amplitude of the Gaussian fit thus corresponded to the protons bound in the crystal structure of the formed portlandite $(\mathrm{CH})$ and the amplitude of the exponential fits corresponded to the protons in the C-S-H structure and the free water $[3,5]$. Figure 2 shows that this proton fraction can be further split into three major reservoirs, in accordance with the existing literature [3], by measuring the CPMG decay of the sample in combination with multiexponential fitting as described above. These reservoirs could be attributed to the protons bound in the C-S-H interlayer space (Exp1, green dashed line), the protons bound in the C-S-H gel pores (Exp2, blue dashed line), and the protons in interhydrate pores (Exp3 and Exp4, light blue and magenta dashed line). For interpretation of the references to color in the figures, the reader is referred to the web version of this article.

The final result of the solid-echo and CPMG measurements with the mean value for the three measured samples after $28 \mathrm{~d}$ of hydration are listed in Table 2. It was also noted that 18.4 at.\% of the protons and thus $18.4 \mathrm{wt} . \%$ of the water in the sample was bound in the $\mathrm{CH}$ structure; $40.8 \mathrm{wt} . \%$ was bound in the C-S-H interlayer and $24.5 \mathrm{wt}$.\% was bound in the C-S-H gel pores. The interhydrate 
pores contained $15.9 \mathrm{wt} . \%$ of the water in the sample. Additionally, Table 2 lists the mean value for the determined $T_{2}$ times for each proton reservoir, which were used in the next sections to calibrate the surface relaxivity and to calculate the corresponding planar or spherical pore diameters.

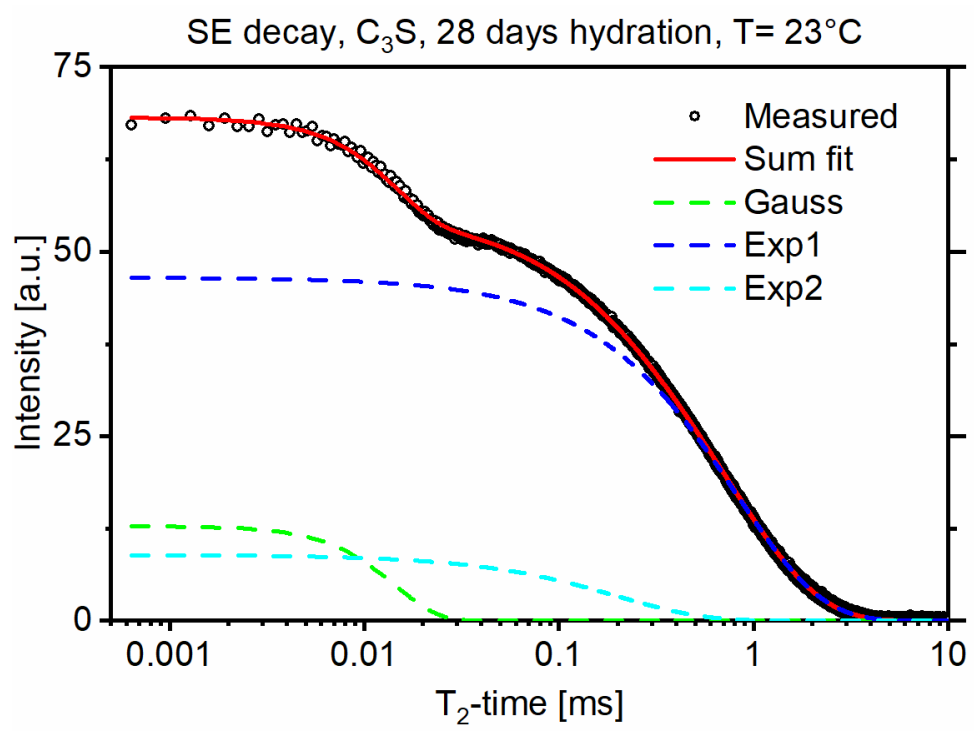

Figure 1. Solid-echo decay of a $28 \mathrm{~d}$ hydrated $\mathrm{C}_{3} \mathrm{~S}$ sample (black circles) with the Gaussian and exponential decay fits.

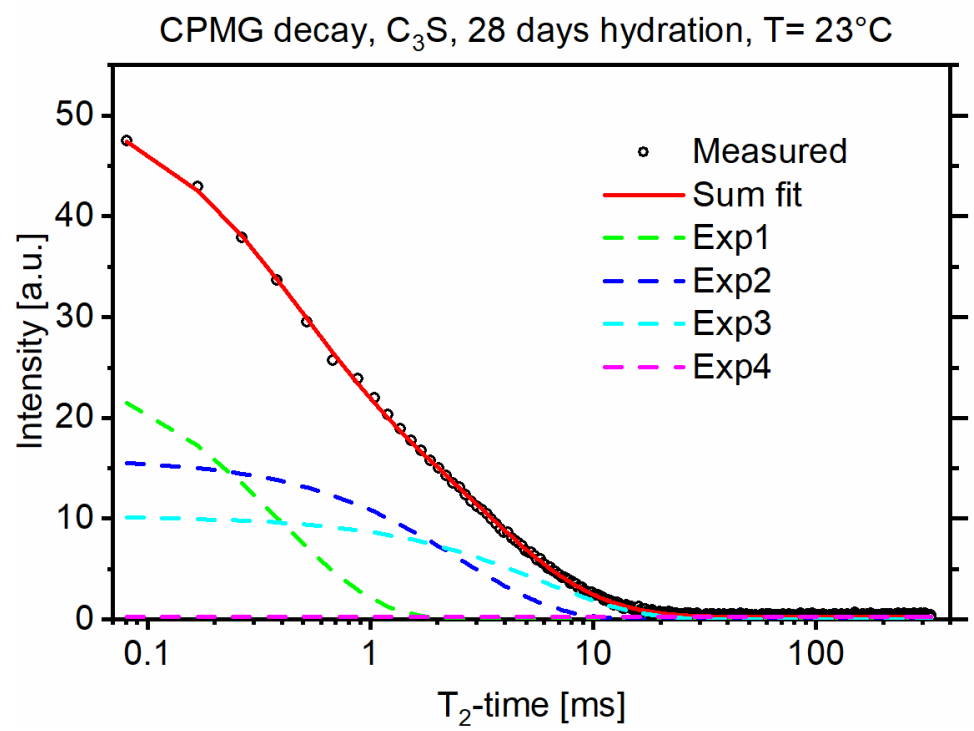

Figure 2. CPMG decay of a 28-d hydrated $\mathrm{C}_{3} \mathrm{~S}$ sample (black circles) with the multiexponential fitting results using four exponential decay functions.

Table 2. H reservoir distribution resulting from the evaluation of the solid-echo and CPMG decay results.

\begin{tabular}{ccc}
\hline H Reservoir & H Fraction [at. \%] & $\boldsymbol{T}_{\mathbf{2}}[\boldsymbol{\mu} \mathbf{s}]$ \\
\hline Portlandite $(\mathrm{CH})$ & $18.4 \pm 0.3$ & $14.1 \pm 0.1$ \\
C-S-H interlayer & $40.8 \pm 0.2$ & $407 \pm 10$ \\
C-S-H gel pores & $24.5 \pm 0.2$ & $2694 \pm 110$ \\
Interhydrate pores & $15.9 \pm 0.3$ & $6089 \pm 151$ \\
\hline
\end{tabular}




\subsection{Monolayer $\mathrm{H}_{2} \mathrm{O}$ Coverage Relaxation}

The $T_{2}$ relaxation time for the interlayer protons at high drying conditions was determined to be $310 \mu$ s. Considering planar pores, where $S / V=2 / d$ according to Section 2.2 and a water monolayer thickness of $0.28 \mathrm{~nm}$ as half the distance for the planar interlayer pore space, Equation (1) delivered a value of $9.0 \times 10^{-4} \mathrm{~nm} / \mu$ s for the surface relaxivity calibrated by this method. Calculated from this surface relaxivity, the pore diameters for the proton reservoirs, listed in Table 2 with their corresponding $T_{2}$ times, were $0.72 \mathrm{~nm}$ for the C-S-H interlayer and $4.9 \mathrm{~nm}$ for the C-S-H gel pores considering a planar pore geometry. The calculated pore diameter for the interhydrate pores was $33 \mathrm{~nm}$ assuming a spherical pore geometry.

\subsection{Combination of SEM and TD-NMR}

Two exemplary high resolution SEM images of the 28-d hydrated $C_{3} S$ samples are shown in Figure $3 a-d$. The interhydrate pore space is clearly visible, as well as the overgrowing inner and outer product C-S-H phase. The two images on the left side show the acquired SEM images. Figure $3 b$ and $3 \mathrm{~d}$ show the image analysis results with the segmented pore space colored in green. It is obvious that segmentation of smaller pores (Figure $3 \mathrm{~b}$ is more precise than for larger pores (Figure $3 \mathrm{~d}$ ).
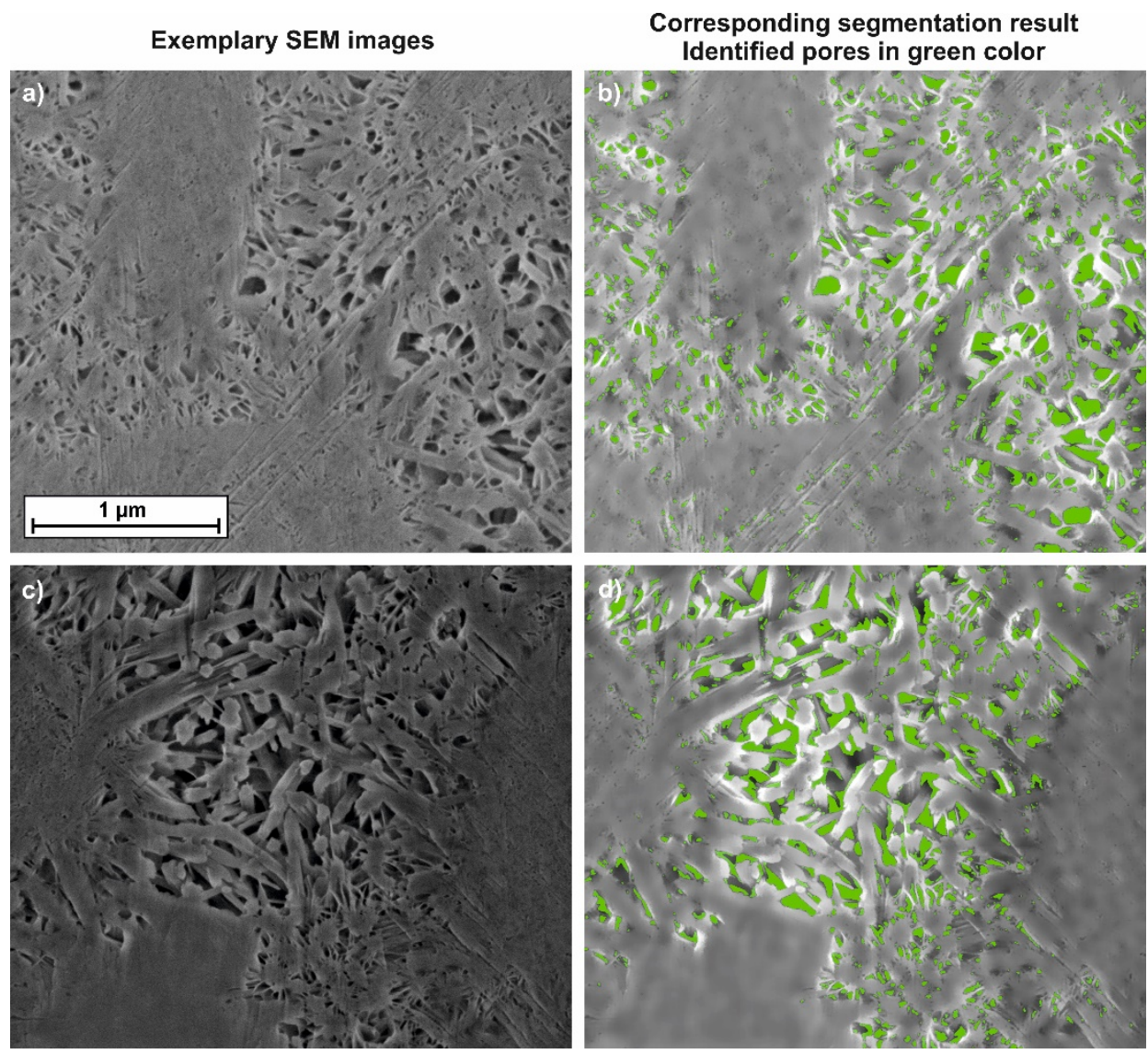

Figure 3. Two exemplary image segmentation results. The acquired SEM images $(\mathbf{a}, \mathbf{c})$ and the resulting segmentation with the pores in green $(\mathbf{b}, \mathbf{d})$. All images have the same scale bar.

Figure 4 shows the resulting interhydrate pore size distribution derived from the segmented image analysis of the samples as described in Section 2.2.2. In this distribution, one bin spans $3 \mathrm{~nm}$ in size on the $x$-axis. All the pores with a diameter smaller than $6 \mathrm{~nm}$ are represented in the first bin. The second bin contains pores with between 6 and $9 \mathrm{~nm}$ diameters and so forth. 
The number of pores is plotted on the left $y$-axis in Figure 4. There was a high number of relatively small pores and the number of pores decreased exponentially with pore size. The mean pore size weighted by the total number of pores was $28.4 \mathrm{~nm}$. The cumulative number of pores in $\%$ is shown on the right $y$-axis in Figure 4.

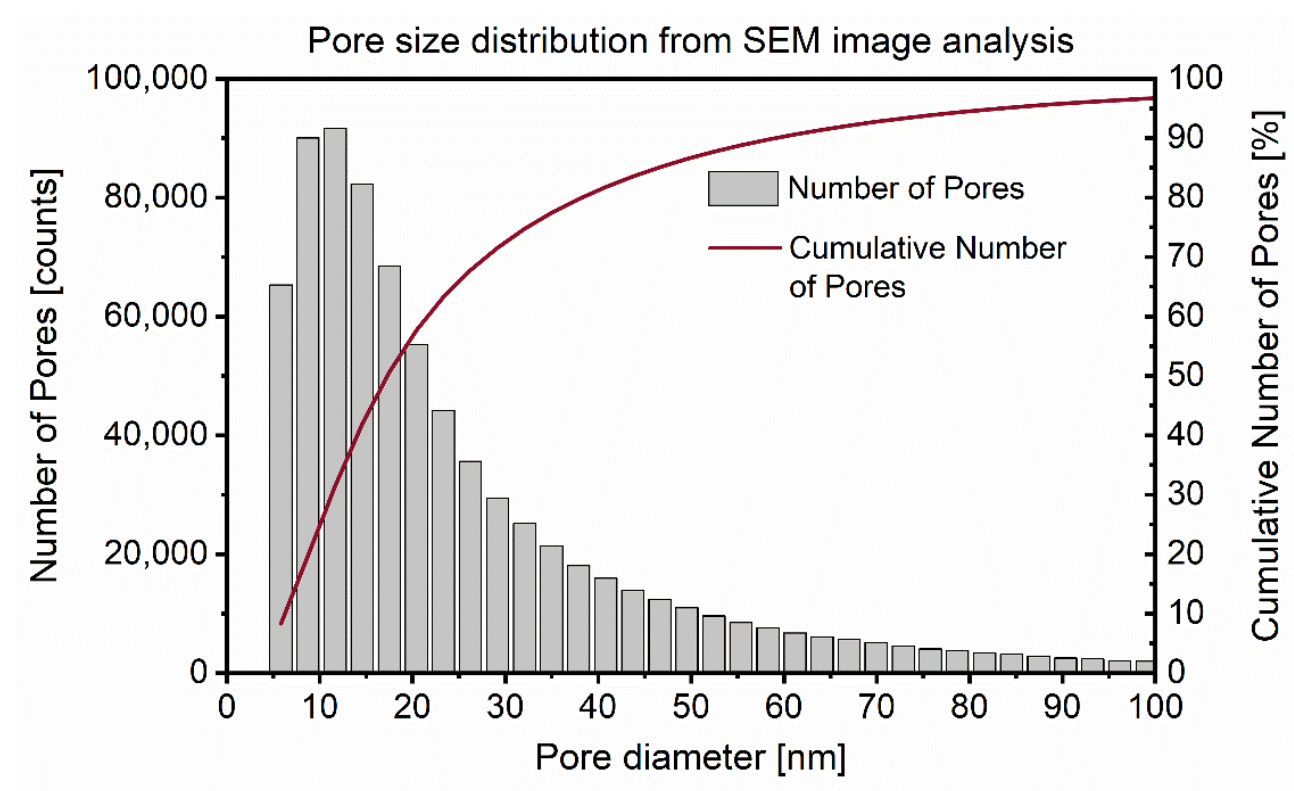

Figure 4. Interhydrate pore size distribution from automated image analysis of Ar-BIB milled $28 \mathrm{~d}$ hydrated $\mathrm{C}_{3} \mathrm{~S}$ samples. The chord-length density function (CDF) was determined as pore diameter.

However, for the surface relaxivity calibration (Equation (1)) it is not the number of pores of different sizes, but rather the total pore surface and volume that have a direct influence on the proton relaxation. For pores with an increasing diameter, an increasing deviation from the assumed spherical pore shape and increasing interconnectedness was observed, leading to increasing underestimation of surface-to-volume ratio. Therefore, the calibration of the surface relaxivity was calculated based on the ratio of the sums of surface and volume of all pores smaller than $100 \mathrm{~nm}$, attributing to $97 \%$ of the total pore count.

The resultant surface-to-volume ratio of $0.11 \mathrm{~nm}^{-1}$ was used for the surface relaxivity calibration. Considering spherical pores and the $T_{2}$ relaxation time for interhydrate pores of $6089 \mu$ s, this resulted in a surface relaxivity of $1.49 \times 10^{-3} \mathrm{~nm} / \mu$ s employing the relationship in Equation (1). According to the $T_{2}$ times for C-S-H gel pores and the C-S-H interlayer shown in Table 2, this led to planar pore diameters of 8.1 and $1.2 \mathrm{~nm}$ as shown in Table 3.

Table 3. Surface relaxivity and pore sizes calibrated via monolayer $\mathrm{H}_{2} \mathrm{O}$ coverage and SEM-NMR combination compared to literature values.

\begin{tabular}{ccccc}
\hline Calibration Method & $\begin{array}{c}\text { Surface Relaxivity } \\
{[\mathbf{n m} / \mu \mathbf{s}]}\end{array}$ & $\begin{array}{c}\text { C-S-H Interlayer } \\
{[\mathbf{n m}]}\end{array}$ & $\begin{array}{c}\text { C-S-H Gel Pores } \\
{[\mathbf{n m}]}\end{array}$ & $\begin{array}{c}\text { Interhydrate Pores } \\
{[\mathbf{n m}]}\end{array}$ \\
\hline $\begin{array}{c}\text { Monolayer } \mathrm{H}_{2} \mathrm{O} \\
\text { coverage }\end{array}$ & $9.0 \times 10^{-4}$ & 0.72 & 4.9 & 33 \\
\hline $\begin{array}{c}\text { Combination } \\
\text { SEM-NMR }\end{array}$ & $1.49 \times 10^{-3}$ & 1.2 & 8.1 & 54 \\
\hline From Muller et al. [3] & $3.73 \times 10^{-3}$ & 0.94 & 3.1 & - \\
\hline
\end{tabular}

\subsection{Comparison of the Two Methods Employed for Surface Relaxivity Calibration}

The main results of the two surface relaxivity calibration methods, the drying method assuming monolayer $\mathrm{H}_{2} \mathrm{O}$ coverage and the combination of SEM and NMR, are shown in Table 3. Considering 
the two completely different approaches, the resulting surface relaxivity values of $0.9 \times 10^{-3}$ and $1.49 \times 10^{-3} \mathrm{~nm} / \mu$ s were quite comparable. Consequently, the calculated pore sizes for C-S-H interlayer pores, C-S-H gel pores, and interhydrate pores were also comparable. Furthermore, the interlayer and gel pore sizes obtained in this study were comparable to the $0.94 \mathrm{~nm}$ and $3.1 \mathrm{~nm}$ reported by Muller et al. [3] for a hydrated white cement paste. Their $T_{2}$ relaxation was faster due to a different chemistry of the samples with a surface relaxivity value of $3.73 \times 10^{-3} \mathrm{~nm} / \mu \mathrm{s}$.

The surface relaxivity calibration through a combination of SEM image analysis and TD-NMR presented in this work confirmed the drying method proposed in the literature $[3,7,8]$. This was, however, only possible by employing a careful sample preparation routine presented in Section 2.2.2 as to not destroy the interhydrate pore space of the hydrated samples. It has to be noted that the presented new surface relaxivity calibration method relies on measured physical data, i.e., the pore sizes from SEM image analysis. No assumptions need to be made about the physico-chemical conditions of the C-S-H interlayer space, in particular the monolayer $\mathrm{H}_{2} \mathrm{O}$ coverage of the interlayer pore surface. Therefore, compared to the monolayer calibration method, the new method relies on fewer assumptions.

As the image analysis demonstrates (Figure 4), there was a wide range of interhydrate pore sizes spanning from around $6 \mathrm{~nm}$ to over $100 \mathrm{~nm}$. Additionally, those pores were far from being perfectly spherical. Thus, the resulting values for pore diameters shown in Table 3 should be seen as approximate mean values and might not fully reflect the complex nature of nanoscale pore spaces. Recent advances in three-dimensional combined focused ion beam/scanning electron microscopy (FIB/SEM) sectioning and image analysis of hydrated cements are likely to enable a more detailed characterization of the pore surface, volume and shape in the future [21].

In line with previous authors, we chose the fast exchange model with a single relaxation time valid for all surfaces in the sample. Since it was sensitive to the surface chemistry, it may have been affected by the chemical composition and the phases present in the sample and may have been different in small and larger pores. Interestingly, since most phases other than C-S-H were crystalline without an internal porosity, they should have contributed to the surface of the larger pores and should therefore have had a stronger effect on the surface relaxivity of the new method. In the monolayer method, the contribution of the phases should be weighted by their contribution to the total surface. Thus, the surface relaxivity obtained by this method should be more characteristic for the internal C-S-H porosity. This could assign a physical meaning to the two different values of the surface relaxivity found. It would have been inappropriate to do so in our experiments due to the uncertainties of the averaging processes involved. More refined future experiments may indeed extend these ideas towards differentiating between the surface relaxivities in both pores.

\section{Conclusions}

- $\quad$ The new method for the NMR surface relaxivity calibration presented in this work relies on a combined analysis of SEM images and ${ }^{1} \mathrm{H}$-TD-NMR measurements.

- $\quad$ Argon broad ion beam sectioning allowed us to preserve and image the interhydrate pore space of hydrated tricalcium silicate with high resolution.

- $\quad$ The acquired results were comparable to the results obtained by an already established drying method, assuming monolayer $\mathrm{H}_{2} \mathrm{O}$ coverage.

- In contrast to this established method, the new method presented does not solely rely on NMR measurements and assumptions about the physico-chemical conditions of the sample surface.

- The physical parameters determined by this pore size characterization are important for models of the nanostructure of C-S-H, such as [22,23].

- Apart from being relevant for fundamental research, the method presented could also help in the design of new mortar and concrete formulations.

Author Contributions: Conceptualization, C.N., F.K., and L.N.-T.; investigation, C.N., F.K., and C.R.; data curation, C.N., F.K., and F.B.; software, F.K.; writing-original draft preparation, C.N.; writing-review and editing, all 
authors; visualization, C.N., F.K., and F.B.; supervision, C.R. and J.N.; funding acquisition, C.R., M.A.E., and J.N. All authors have read and agreed to the published version of the manuscript.

Funding: This research was funded by the German Research Foundation (Deutsche Forschungsgemeinschaft) (grant numbers: Lu1652/30-1 and Ne813/6-1).

Acknowledgments: The authors would like to thank P.J. McDonald and A.M. Gajewicz-Jaromin for the fruitful discussion and the helpful insights concerning the NMR measurements.

Conflicts of Interest: The authors declare no conflicts of interest.

\section{References}

1. Muller, A.C.A.; Scrivener, K.L. A reassessment of mercury intrusion porosimetry by comparison with $1 \mathrm{H}$ NMR relaxometry. Cem. Concr. Res. 2017, 100,350-360. [CrossRef]

2. Zhang, J.; Scherer, G.W. Comparison of methods for arresting hydration of cement. Cem. Concr. Res. 2011, 41, 1024-1036. [CrossRef]

3. Muller, A.C.A.; Scrivener, K.L.; Gajewicz, A.M.; McDonald, P.J. Use of bench-top NMR to measure the density, composition and desorption isotherm of C-S-H in cement paste. Microporous Mesoporous Mater. 2013, 178, 99-103. [CrossRef]

4. McDonald, P.J.; Rodin, V.; Valori, A. Characterisation of intra-and inter-C-S-H gel pore water in white cement based on an analysis of NMR signal amplitudes as a function of water content. Cem. Concr. Res. 2010, 40, 1656-1663. [CrossRef]

5. $\quad$ Ectors, D.; Goetz-Neunhoeffer, F.; Hergeth, W.D.; Dietrich, U.; Neubauer, J. In situ 1H-TD-NMR: Quantification and microstructure development during the early hydration of alite and OPC. Cem. Concr. Res. 2016, 79, 366-372. [CrossRef]

6. Jansen, D.; Naber, C.; Ectors, D.; Lu, Z.; Kong, X.-M.; Goetz-Neunhoeffer, F.; Neubauer, J. The early hydration of OPC investigated by in-situ XRD, heat flow calorimetry, pore water analysis and ${ }^{1} \mathrm{H}$ NMR: Learning about adsorbed ions from a complete mass balance approach. Cem. Concr. Res. 2018, 109. [CrossRef]

7. Brownstein, K.R.; Tarr, C.E. Importance of classical diffusion in NMR studies of water in biological cells. Phys. Rev. A. 1979, 19, 2446-2453. [CrossRef]

8. Cohen, M.H.; Mendelson, K.S. Nuclear magnetic relaxation and the internal geometry of sedimentary rocks. J. Appl. Phys. 1982, 53, 1127-1135. [CrossRef]

9. Desbois, G.; Urai, J.L.; Kukla, P.A.; Konstanty, J.; Baerle, C. High-resolution 3D fabric and porosity model in a tight gas sandstone reservoir:A new approach to investigate microstructures from mm-to nm-scale combining argon beam cross-sectioning and SEM imaging. J. Pet. Sci. Eng. 2011, 78, 243-257. [CrossRef]

10. McDonald, P.J.; Gajewicz, A.M.; Morrell, R. The characterisation of cement based materials using T2 $1 \mathrm{H}$ nuclear magnetic resonance relaxation analysis. 2017. Available online: http://eprintspublications.npl.co.uk/7365/ (accessed on 9 April 2020).

11. Yermakou, V. Study of the transport of water in the nanopores of C-S-H by 1H NMR. Ph.D. Thesis, Department of Mechanical Engineering and Sciences, University of Surrey, Guildford, UK, 2017.

12. D'Orazio, F.; Bhattacharja, S.; Halperin, W.P.; Eguchi, K.; Mizusaki, T. Molecular diffusion and nuclear-magnetic-resonance relaxation of water in unsaturated porous silica glass. Phys. Rev. B. 1990, 42, 9810-9818. [CrossRef] [PubMed]

13. Powles, J.G.; Strange, J.H. Zero time resolution nuclear magnetic resonance transient in solids. Proc. Phys. Soc. 1963, 82, 6-15. [CrossRef]

14. Carr, H.Y.; Purcell, E.M. Effects of diffusion on free precession in nuclear magnetic resonance experiments. Phys. Rev. 1954, 94, 630-638. [CrossRef]

15. Meiboom, S.; Gill, D. Modified spin-echo method for measuring nuclear relaxation times. Rev. Sci. Instrum. 1958, 29, 688-691. [CrossRef]

16. Israelachvili, J.N. Intermolecular and Surface Forces; Elevier: Amsterdam, The Netherlands, 2011.

17. Schindelin, J.; Arganda-Carreras, I.; Frise, E.; Kaynig, V.; Longair, M.; Pietzsch, T.; Preibisch, S.; Rueden, C.; Saalfeld, S.; Schmid, B.; et al. Fiji: An open-source platform for biological-image analysis. Nat. Methods 2012, 9, 676-682. [CrossRef] [PubMed]

18. Kleiner, F. GitHub Profile. 2019. Available online: https://github.com/kleinerELM/supported_manual_ segmentation (accessed on 9 April 2020). 
19. Phansalkar, N.; More, S.; Sabale, A.; Joshi, M. Adaptive local thresholding for detection of nuclei in diversity stained cytology images. In Proceedings of the ICCSP 2011: International Conference on Communications and Signal Processing, Calicut, India, 10-12 February 2011; pp. 218-220. [CrossRef]

20. Torquato, S. Random Heterogeneous Materials; Springer New York: New York, NY, USA, 2002. [CrossRef]

21. Möser, B.; Rössler, C.; Ludwig, H.-M. Recent Developments in Analytical SEM Techniques Combined with Focused Ion Beam Sectioning to Image the 3D Nanostructure of Hydrated Cements. In Proceedings of the 15th International Congress on the Chemistry of Cement (ICCC 2019), Prague, Czech Republic, 16-20 September 2019.

22. Etzold, M.A.; McDonald, P.J.; Routh, A.F. Growth of sheets in 3D confinements-A model for the C-S-H meso structure. Cem. Concr. Res. 2014, 63, 137-142. [CrossRef]

23. Nguyen-Tuan, L.; Etzold, M.A.; Rößler, C.; Ludwig, H.-M. Growth and porosity of C-S-H phases using the sheet growth model. Cem. Concr. Res. 2020, 129, 105960. [CrossRef]

(C) 2020 by the authors. Licensee MDPI, Basel, Switzerland. This article is an open access article distributed under the terms and conditions of the Creative Commons Attribution (CC BY) license (http://creativecommons.org/licenses/by/4.0/). 